\title{
ПРОГРАММА ИМПОРТОЗАМЕЩЕНИЯ
}

\section{НА ПРЕДПРИЯТИИ}

"ГРУППА КРЕМНИЙ ЭЛ":

ПОЛИМЕРНОЕ КОРПУСИРОВАНИЕ

\author{
О.Кочегин, В.Громов, Н.Брюхно, М.Котова, Е.Абашин, В.Огнев
}

УДК 621.363

BAK 05.27.06

\author{
ЗАО "Группа Кремний ЭЛ" прочно занимает второе место в России \\ по выпуску изделий микроэлектроники для нужд Минобороны РФ. \\ Вся предлагаемая преприятием продукция разработана \\ специалистами "Группы Кремний эл" и поставляется более 700 \\ заказчикам, среди которых ведущие российские производители \\ вооружений, такие как ОАО "Корпорация "Тактическое ракетное \\ вооружение", ОАО "Концерн ПВО "Алмаз-Антей", ОАО "Корпорация \\ "Аэрокосмическое оборудование", ОАО "Концерн "Созвездие", \\ ОАО "Концерн радиостроения "Вега" и др. За 2000-2015 годы \\ ЗАО "Группа Кремний ЭЛ" в восемь раз увеличило объем \\ и на четверть обновило товарную продукцию. О ее качестве \\ и надежности говорит тот факт, что количество отказов составляет \\ один на миллион изделий. Для достижения таких результатов \\ на предприятии осуществили техническое перевооружение \\ производства, в рамках которого было закуплено современное \\ технологическое оборудование.
}

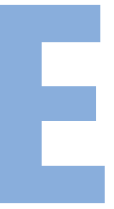
жегодно ЗАО "Группа Кремний ЭЛ" участвует в государственных целевых конкурсах на создание инновационных продуктов, предприятие активно работает и по федеральной программе импортозамещения, которая за последние два года стала основным фактором развития отраслей отечественной экономики. В первую очередь к реализации этой программы приступили предприятия оборонной промышленности.

В 2016 году ЗАО "Группа Кремний ЭЛ" участвовало в восьми конкурсах по импортозамещению в сфере микроэлектроники по направлениям своей специализации: вторичное электропитание, шимконтроллеры, линейные и импульсные стабилизаторы, транзисторы биполярные, диоды выпрямительные и Шоттки, интегральные схемы драйверов управления IGBT-и ДМОП-транзисторов.
В соответствии с программой импортозамещения на предприятии была решена проблема полимерного корпусирования ИС - разработан новый полимерный материал. Связующей основой материала служит смесь фенолоформальдегидной и кремнийорганических смол, в качестве наполнителя применяются кварц и синтетический аморфный диоксид кремния. Полученный реактопласт отличается хорошей адгезией к металлам, повышенными теплостойкостью и влагостойкостью, свободен от ионов $\mathrm{Na}^{+}$и $\mathrm{Cl}^{-}$и не выделяет влагу.

\section{ПРОБЛЕМА ИМПОРТОЗАМЕЩЕНИЯ В КОРПУСИРОВАНИИ}

За последние 50 лет металлокерамические корпуса микросхем и полупроводниковых приборов заслужили репутацию надежных элементов конструкции для жестких условий эксплуатации. 
Но в ряде случаев (при использовании в малогабаритных изделиях, для поверхностного монтажа, в СВч- и силовой электронике) начинают существенно сказываться их недостатки: высокое тепловое сопротивление и омическое сопротивление выводов, а также высокая цена, обусловленная конструкцией и технологией производства корпусов. В то же время термореактивные пластмассовые (полимерные) корпуса, широко используемые для герметизации микросхем и полупроводниковых приборов бытового и промышленного назначения, лишены этих недостатков. Однако они практически не применяются в системах, предназначенных для жестких условий эксплуатации.

Анализ основных характеристик металлополимерных (металлокомпозитных) корпусов на основе современных композитных материалов показал, что последние по качеству не уступают металлокерамическим, а по технологичности - пластмассовым корпусам. В качестве альтернативы их можно использовать в жестких и специальных условиях эксплуатации.

В последнее время несколько изменилось отношение к полимерным корпусам, что, скорее всего, связано с реализацией департаментом радиоэлектронной промышленности Минпромторга программ импортозамещения и нежеланием (а иногда и невозможностью) внедрения их результатов предприятиямизаказчиками и организациями ОПК. Эти проблемы неоднократно обсуждались на многочисленных конференциях и совещаниях с участием представителей разработчиков и изготовителей полупроводниковых приборов и микросхем, разработчиков и изготовителей радиоэлектронных устройств для специального применения, в которых используются зарубежные микросхемы и полупроводниковые приборы в пластмассовых корпусах.

Лейтмотив и преобладающее настроение состоявшихся обсуждений, встреч как нельзя точно характеризует следующий диалог, в котором для краткости участники - изготовители элементной базы и предприятия ОПК условно именуются "Э" и "П", соответственно:

П: Для импортозамещения нужна микросхема только "pin-to-pin".

Э: Вот она.

П: Да? А Электрические параметры один в один?

Э: Один в один.

П: И приемка есть?

Э: Категория качества ВП.

П: А радиационной стойкости нет!

Э: А вот и есть!

П: (Задумчиво и глубокомысленно) Но она же пластмассовая!?
Как же так? Получается, что зарубежную ширпотребовскую микросхему не радиационно-стойкую, без приемки, зачастую без расширенного температурного диапазона применять в аппаратуре ОПК можно, а отечественную с приемкой ВП, радиационно-стойкую, с рабочим диапазоном температур от -60 до $125^{\circ} \mathrm{C}$ и лучшей стойкостью к климатическим воздействиям - нельзя?!

Что же изменилось в критических подходах к полимерным изделиям отечественного производства, да и в целом в отношении "пластмассы"? И так как авторы не понимают разницы между зарубежной и отечественной пластмассой широкого потребления (она уже давно одна и та же, а именно: производства фирм Henkel, Hitachi Chemical и др.), то рассмотрим проблему на примере полимерных корпусов производства зАО "Группа Кремний ЭЛ". Сразу же уточним, что полимерные корпуса уже давно не "пластмасса", а композит, то есть полимерная основа с минеральными наполнителями (кварц, диоксид кремния и т.п.).

\section{АНАЛИЗ КРИТИКИ ПОЛИМЕРНОГО КОРПУСИРОВАНИЯ}

Основные критические замечания относительно полимерного корпусирования ИЭТ сводятся к давно известным положениям:

- наличие ионов $\mathrm{Cl}^{-}$и $\mathrm{Na}^{+}$;

- негерметичность из-за разницы в ТКЛР полимера и металла выводной рамки;

- горючесть.

Среди новых аргументов можно отметить выделение влаги и низкую температурную стойкость.

Неоднократно в печати были ссылки [1-5] на публикации о несостоятельности такой критики.

Во-первых, в рецептуре и в процессе формирования современного, как импортного, так и отечественного, полимера отсутствуют $\mathrm{Na}$ и $\mathrm{CL}$, что подтверждается спецификациями на эти материалы и результатами их испытаний.

Во-вторых, негерметичность полимерного корпусирования значительно снижена [6] благодаря применению следующих решений:

- использование материалов корпуса с близкими ТКЛР:

- введение между полимером и выводной рамкой связующего адгезива;

- введение в конструкцию кристаллодержателя "замков герметичности".

В-третьих, стойкость к горению обеспечена рецептурой полимера и подтверждена результатами испытаний (о которых скажем дополнительно). 
Прежде чем ответить на новые аргументы критических замечаний (выделение влаги, низкая температурная стойкость), попробуем разобраться, каким должен быть полимерный корпус?

Рассмотрим требования, которые предъявляются конечными потребителями микроэлектронной техники к используемому изделию.

\section{Требования к корпусу}

- При нагреве во время работы и даже в случае электрического и теплового пробоя корпус не должен претерпевать изменений с точки зрения физикомеханических и электрических свойств. Если температурно-временные воздействия превысят стойкость материала, то продукты его деструкции должны быть нетоксичными.

- Материал корпуса не должен содержать компоненты, способные оказывать влияние на качество и работоспособность ИС, то есть он должен быть инертным.

- Корпус Ис должен быть влагоустойчивым, а в идеале - водоотталкивающим.

- Материал корпуса должен обеспечивать абсолютную герметичность при разнице давлений внутри и снаружи корпуса в пределах его механической прочности.

- Обеспечивать радиационную защиту кристалла ИС. На практике все электрические и физико-механические характеристики должны быть на уровне, превышающем рабочие условия эксплуатации. Обычные термопласты (полиэтилен, полипропилен, ПЭТФ, полиамид и т.д.) при нагревании плавятся, поэтому о сохранении физико-механических свойств при нагреве выше $150{ }^{\circ} \mathrm{C}$ говорить не приходится. Но есть группа пластмасс, называемая реактопластами. Окончательную структуру они приобретают в результате реакции полимеризации при химическом либо физическом воздействии. Эта реакция необратима, конечный продукт повторной переработке не подлежит.
К этой группе относятся эпоксидные, полиэфирные, фенолоформальдегидные, кремнийорганические и другие пластмассы, способные выдерживать достаточно высокие температуры (до $400^{\circ} \mathrm{C}$ ) без изменений механических и электрических свойств. Такие термостойкие реактопласты используются в качестве полимерной основы (связующего) нового материала для полимерных корпусов и обеспечивают все виды монтажа кристалла в корпус (пайка, эвтектика, клей).

\section{ПОВЫШЕНИЕ ВЛАГОСТОЙКОСТИ, ГЕРМЕТИЧНОСТИ И ТЕПЛОСТОЙКОСТИ}

По результатам исследований термоустойчивых полимеров [7] были выбраны две связующие основы - кремнийорганическая и фенолоформальдегидная (табл.1).

Достоинства и недостатки фенолоформальдегидных полимеров, которые широко используются в микроэлектронике, хорошо изучены. Кремнийорганические полимеры являются промежуточным звеном между органическими и неорганическими материалами. В их состав, кроме углерода С (характерного для органических полимеров), входит кремний Si. Основу строения их молекул образует силоксанная цепь чередующихся атомов кремния и кислорода. Кремнийорганические полимеры могут быть термопластичными с линейным строением и термореактивным с образованием пространственных структур. Энергия силоксановой связи $\mathrm{Si-O}$ больше, чем энергия связи между двумя атомами углерода С-C, что и определяет более высокую температурную стойкость кремнийорганических полимеров по сравнению с органическими. Атом кремния связан с кислородом, не может окисляться дальше, поэтому молекулы образовавшегося полимера при нагревании не распадаются, и вещество характеризуется повышенной рабочей температурой.

Кремнийорганические полимеры отличаются высокими электроизоляционными свойствами, стойкостью

Таблица 1. Электрические свойства отвержденных реактопластов на базе связующих полимеров

\begin{tabular}{|c|c|c|c|c|}
\hline \multirow[b]{2}{*}{ Связующий полимер } & \multicolumn{4}{|c|}{ Характеристики } \\
\hline & $\begin{array}{c}\text { удельное объемное } \\
\text { электрическое сопро- } \\
\text { тивление, } \\
\text { Ом·см }\end{array}$ & $\begin{array}{c}\text { тангенс угла } \\
\text { диэлектрических } \\
\text { потерь }\end{array}$ & $\begin{array}{c}\text { диэлектрическая } \\
\text { проницаемость }\end{array}$ & $\begin{array}{c}\text { электрическая } \\
\text { прочность, } \\
\text { кВ/мм }\end{array}$ \\
\hline Фенолоформальдегидный & $10^{11}-10^{12}$ & $0,015-0,035$ & $3,0-5,0$ & $12-16$ \\
\hline Кремнийорганический & $10^{14}-10^{16}$ & $0,001-0,025$ & $2,6-4,2$ & $20-30$ \\
\hline
\end{tabular}


Таблица 2. Сравнение характеристик реактопластов

\begin{tabular}{|l|c|c|}
\hline \multirow{2}{*}{ Параметр } & \multicolumn{2}{|c|}{ Материал } \\
\cline { 2 - 3 } & ЗАО "Группа Кремний эл" & HYSOL KL-1000-3A \\
\hline Внешний вид & Незначительное количество облоя & Обильный облой на радиаторе \\
\hline Предельная температура, ${ }^{\circ} \mathrm{C}$ & $\geq 400$ \\
\hline $\begin{array}{l}\text { Устойчивость к горению (пламя } \\
\text { зажигалки) }\end{array}$ & Обугливание и возгорание \\
\hline воде происходило & Дым выделяется слабо, \\
слабо обугливается
\end{tabular}

к дуговому разряду, теплостойкостью (способны длительно выдерживать температуру до $200^{\circ} \mathrm{C}$ и кратковременно $\left.-500^{\circ} \mathrm{C}\right)$, водостойкостью (гидрофобностью), не смачиваются водой, так как образуют на поверхности тончайшую пленку, которая не впитывается и не пропускает воду, а также устойчивостью к грибковой плесени и высокой морозостойкостью. Недостатки - плохая адгезия к большинству других материалов, низкая маслостойкость, достаточно высокая стоимость.

Связующее на основе смеси фенолоформальдегидной и кремнийорганической смол по определению увеличит теплостойкость полимера и обеспечит необходимые электрические и физико-механические свойства. Но для получения качественного полимера с требуемыми параметрами одной связующей основы недостаточно. Ее надо взять за базу, наполнив как матрицу различными компонентами, придающими те или иные свойства [8].

В первую очередь нужен наполнитель, способный компенсировать разницу КТлР металла выводной рамки $\left(16,6 \cdot 10^{-6} \mathrm{~K}^{-1}\right)$ и полимера $\left(80 \cdot 10^{-6} \mathrm{~K}^{-1}\right)$. Наиболее подходящим для этого компонентом является кварц, который имеет КТЛР $0,77 \cdot 10^{-6} \mathrm{~K}^{-1}$. Чтобы компенсировать разницу в КТЛР, концентрация кварца должна быть на уровне 65-75\%. Но следует помнить и о таком неординарном требовании, как радиационная стойкость.

Одним из основных веществ радиационной защиты является барит, который также используется в производстве прессматериалов благодаря высокой химической стойкости. Ввести такое количество наполнителя, сохранив однородность структуры материала, непросто. Нужен специальный компонент, связывающий наполнитель и матрицу. Возникла идея создания концепции изготовления активного наполнителя. Этот наполнитель должен играть роль каркаса. Частицы, связанные между собой, не должны изменять свою структуру при воздействии высоких температур даже при частичной деструкции связующего элемента. Данную функцию в нашем полимере выполняет синтетический аморфный диоксид кремния. Высокая пористость материала позволяет легко аппретировать его любыми активными веществами, например, силанами. Появляется возможность разрабатывать изделия со структурами, практически монолитными по своему составу.

Аппретированный диоксид кремния - гидрофобный продукт, позволяющий создать не только водостойкий, но и, возможно, водоотталкивающий материал.

Частицы диоксида кремния, захватывая концы макромолекул связующего, создают квазикристаллическую структуру, обволакивающую более крупные кристаллы кварца. Тем самым образуется пространственная сетка с кварцевым наполнителем.

\section{РЕЗУЛЬТАТЫ ИСПЫТАНИЯ РАЗРАБОТАННОГО РЕАКТОПЛАСТА}

Испытания реактопласта и его исследование проводились в ЗАО "Группа кремний Эл" на базе корпуса ТО-252 (без полости), причем одновременно испытывались образцы корпуса с использованием серийного реактопласта фирмы Henkel HYSOL KL-1000-3A.

В качестве объектов исследования были взяты фрагменты опрессованных 16-кадровых рамок. Часть из них подверглась термостарению в течение 24 ч при температуре $110^{\circ} \mathrm{C}$. Также исследовались куски полимера из застывшей зоны литника. Все образцы проверялись на устойчивость:

- к нагреву до $265^{\circ} \mathrm{C}$ в течение 30 с;

- горению - пламя газовой горелки (30 c);

- нагреву на электрической плите до $350^{\circ} \mathrm{C}$;

- нагреву в вакуумной печи отжига до $430^{\circ} \mathrm{C}$. 
Таблица 3. Результаты испытаний реактопласта в Институте пластмасс им. Г.С.Петрова

\begin{tabular}{|c|c|c|}
\hline Наименование показателя & $\begin{array}{c}\text { Обозначение НД на метол } \\
\text { испытания }\end{array}$ & $\begin{array}{c}\text { Значение показателя } \\
\text { для образца }\end{array}$ \\
\hline Изгибающее напряжение при разрушении, Мпа & ГОСТ 4648 & 85 \\
\hline Тангенс диэлектрических потерь при частоте $10^{6}$ Гц & ГОСТ 22372 & 0,007 \\
\hline Удельное объемное электрическое сопротивление, Ом·см & ГОСТ 6433,2 & $6,4 \cdot 10^{14}$ \\
\hline Электрическая прочность, кВ/мм & ГОСТ 6433,3 & 13,5 \\
\hline Диэлектрическая проницаемость & ГОСТ 22372 & 4,0 \\
\hline Водопоглощение за 24 ч, \% & ГОСТ 4650 & 0,12 \\
\hline Плотность, г/см & ГОСТ 15139 & 1,807 \\
\hline Коэффициент линейного термического расширения, 1/K & ИСО 11359-2 & $23 \cdot 10^{-6}$ \\
\hline Коэффициент теплопроводности, Вт/мК при T $=22{ }^{\circ} \mathrm{C}$ & ИСО DIS22007-2 & $1,10 \pm 0,05$ \\
\hline Массовая доля хлора, выделяющаяся при горении, \% & $\begin{array}{c}\text { По методике } \\
\text { ГОСТ Р МЭК 60754-1-99 }\end{array}$ & Не обнаружено \\
\hline
\end{tabular}

Наряду с этим оценивалось водопоглощение и качественно определялась адгезия к никелю.

Количественные и качественные сравнительные характеристики (результаты испытаний, проведенных на предприятии) разработанного реактопласта и серийного реактопласта HYSOL KL-1000-3А фирмы Henkel приведены в табл.2.

Параллельно с опробованием нового реактопласта на предприятии материал исследовали в Институте пластмасс им. Г.С.Петрова (табл.3). Результаты испытаний подтверждают, что новый реактопласт имеет отличные характеристики.

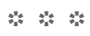

ЗАО "Группа Кремний ЭЛ" разработало российский реактопласт, изготавливаемый только из отечественных материалов, превосходящий по всем характеристикам наиболее распространенный в мировой (в том числе и России) микроэлектронике реактопласт HYSOL KL-1000-3А фирмы Henkel.

Новый реактопласт отличается высокой теплоустойчивостью (до $\left.430^{\circ} \mathrm{C}\right)$, низким влагопоглощением, отсутствием выделения влаги и ионов $\mathrm{Na}^{+}$и $\mathrm{Cl}^{-}$. Стоит подчеркнуть, что это уже не пластмасса, а композиционный полимерный материал (композит), обладающий необходимыми характеристиками для корпусирования ИС специального применения. В настоящее время реактопласт проходит дополнительные обследования на предприятиях соответствующего профиля.

\section{ЛИТЕРАТУРА}

1. Громов В. Металлокомпозитные корпуса с полостьюальтернатива металлокерамическим корпусам микросхем и полупроводниковых приборов // Новые технологии. 2014. № 2. С. 106-112.

2. Боднарь Д. Мощные СВЧ-транзисторы и корпуса для российского и зарубежного рынков // Электронные компоненты. 2013. № 1. С. 1-6.

3. Боднарь Д. Керамические корпуса СВч-транзисторовтуман не рассеивается // Электронные компоненты. 2013. № 3. С. 1-5.

4. Боднарь Д. Пластмассовые корпуса с открытой полостью для интегральной и СВЧ-электроники // Компоненты и технологии. 2016. № 11. С. 137-144.

5. Гудилин Д. Группа Кремний эл: новая отечественная элементная база для силовой электроники // Силовая электроника. 2014. № 8. С. 92-96.

6. Керенцев А., Ланин В. Влагоустойчивость интегральных микросхем в пластмассовых корпусах // Электронные и ионные технологии. 2008. № 4. С. 68-72.

7. Михалин Ю. Термоустойчивые полимеры и полимерные материалы. - СПб.: Профессия, 2006. С. 96.

8. Lu D., Wong C. Materials for advanced packading. Springer International Publishing Switzerland. 2009. 